\title{
Diseases Transmitted by the Black-Legged Ticks in the United States: A Comprehensive Review of the Literature
}

\author{
Juan P. Sosa ${ }^{1}$, Maria M. Ferreira Caceres ${ }^{1}$, Kuchalambal Agadi $^{1}$, Krunal Pandav $^{1}$, Meghana Mehendale ${ }^{1}$, \\ Jayati M. Mehta ${ }^{1}$, Camille Celeste Go ${ }^{2}$, Wanessa Figueiredo. Matos ${ }^{1}$, Prathima Guntipalli ${ }^{1}$, Marie-Pierre \\ E. Belizaire ${ }^{1}$ \\ 1. Division of Research \& Academic Affairs, Larkin Community Hospital, South Miami, USA 2. Family Medicine, Larkin \\ Hospital Palm Springs Campus, Hialeah, USA
}

Corresponding author: Krunal Pandav, krunal.pandav@larkinhospital.com

\begin{abstract}
The black-legged tick is endemic to the midwestern, northeastern, western, south-eastern, and southern regions of the United States. There has been an increased burden of black-legged ticks in humans in recent years. COVID-19 pandemic has further heightened this burden. We thereby reviewed the literature to discuss the seasonality, infections, and clinical spectrum of diseases transmitted by the black-legged ticks. We also discuss the reported delay in the diagnosis of these diseases during the pandemic situation, the alpha-gal syndrome, the importance of prompt diagnosis, and early medical intervention with an aim to increase awareness of the black-legged tick-borne diseases.
\end{abstract}

Categories: Infectious Disease, Public Health, Other

Keywords: black-legged ticks, ixodes scapularis tick, ixodes scapularis, disease, control

\section{Introduction And Background}

The black-legged tick, also known as Ixodes scapularis or I. scapularis, is endemic to the United States, Midwest, northeast, west, southeast, and southern regions [1]. Lyme disease is the most common tick-borne disease transmitted by I. scapularis in the United States [2]. Each year about 3,00,000 cases of Lyme disease are diagnosed in the United States. The causative agent for Lyme disease is Borrelia burgdorferi [3]. Blacklegged ticks are associated with various microorganisms including bacteria, protozoan parasites, and viruses $[4,5]$, summarized in Table 1 .

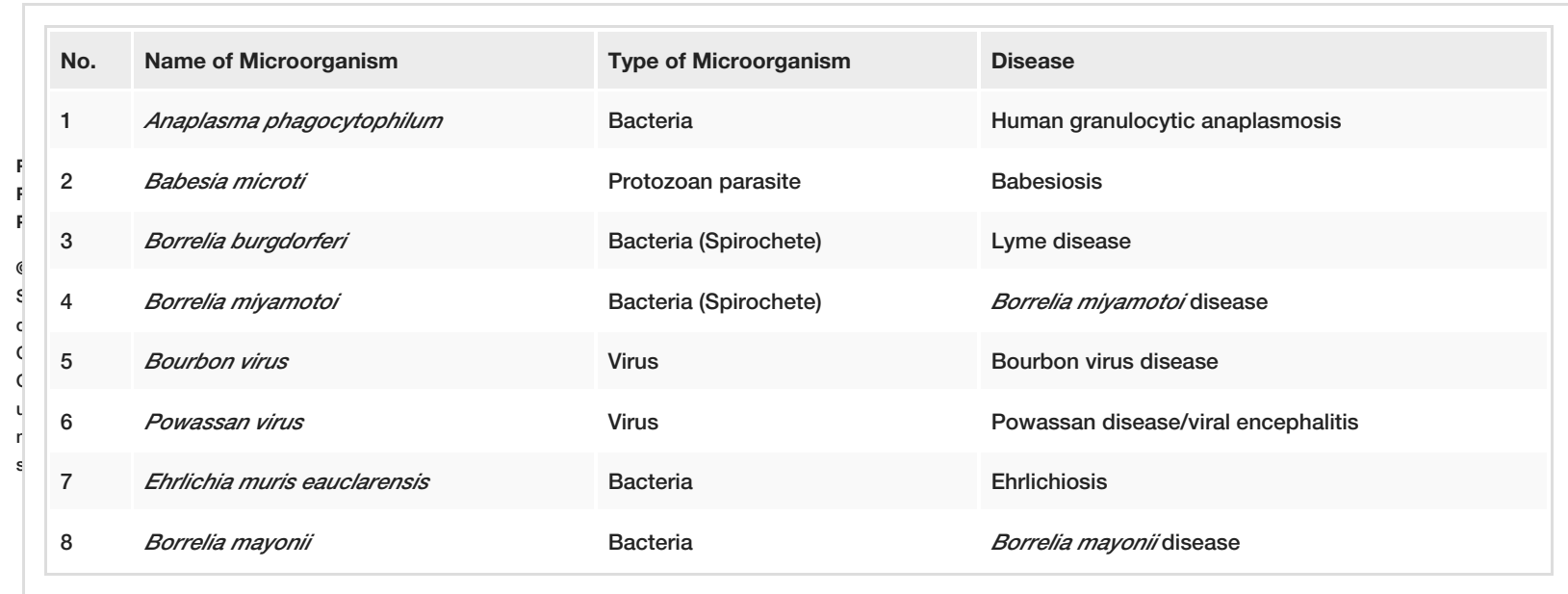

\section{TABLE 1: Microorganisms and diseases associated with black-legged ticks}

The Center for Diseases Control and Prevention (CDC) suggests knowing about the ticks' habitat, i.e., grassy, bushy, or wooded areas, or even on animals; treating the clothing and gear with $0.5 \%$ permethrin; using Environmental Protection Agency (EPA)-registered insect repellents; and avoiding wooded and bushy areas with high grass and leaf litter [6]. Due to tick-borne infections, increased economic burden from a societal perspective was seen before the COVID-19 pandemic [7,8]. Lyme disease could have an estimated burden of $\$ 712$ million to $\$ 1.3$ billion a year on the US healthcare system [9]. The economic burden due to Lyme disease in Maryland in 1997-2000 was approximately \$10,000 per case of Lyme disease, including both direct/indirect medical costs and losses in productivity [8]. These costs are influenced by the severity of the 
disease and stage of diagnosis [10]. Additionally, the COVID-19 pandemic has further heightened the burden due to tick-borne infections, in terms of delay in diagnosis, superadded COVID-19 infection [11,12]. Due to the high burden, research is needed to guide and develop healthcare policy [7]. Moreover, researchers demonstrated that the theory-based tick-borne disease prevention program led to the adoption of precautionary measures by people causing a decreased incidence of tick-borne infections by $60 \%$ [13].

Following this, we present a comprehensive review of the diseases caused by the black-legged ticks in the United States. We also discuss alpha-gal syndrome and the effect of COVID-19 on tick-borne infections in the United States.

\section{Review}

\section{Brief overview of the life cycle of Ixodes scapularis}

I. scapularis belongs to the Ixodidae family, and it takes multiple molts for this tick to reach adulthood. The tick survives for about two to four years $[1,14,15]$. I. scapularis depends on three natural hosts for its blood meal; it is crucial to complete its life cycle, including the larval stage, nymphal stage, and adult $[1,14,15]$. The larva and the nymph have a rodent, Peromyscus leucopus, as their primary host, and a white-tailed deer, Odocoileus virginianus, serves as the host for the mature ticks (adult stage) [1]. Multiple pathogens can be acquired, multiplied, and transmitted due to the midgut and the tick's salivary glands during the blood meal [14-16]. However, the transmission of the Powassan virus and Borrelia Miyamotoi is known to occur transovarially as well. Transmission of pathogens to humans, carried by I. scapularis, mainly occurs during the nymphal stage [14]. The nymphs molt into mature ticks in their second year during autumn [14]. Female adult ticks feed on the white-tailed deer, whereas male adult ticks do not require a blood meal to survive. Male ticks die after mating, and the female ticks are known to lay eggs in thousands during May [14].

\section{Black-legged tick-borne Infections in the United States}

\subsection{Anaplasma phagocytophilum}

Anaplasma phagocytophilum belongs to the Rickettsiale order. It is an obligate intracellular gram-negative bacteria [17,18]. It causes anaplasmosis, also known as human granulocytic anaplasmosis (HGA) [19].

The CDC had reported an increased number of anaplasmosis cases from 348 in 2000 to 5,762 in 2017. On the other hand, in 2018, 4008 cases of anaplasmosis were reported. The majority of the patients registered were males above 40 years of age. The case fatality rate was persistently low $(<1 \%)$ [20]. Anaplasmosis and ehrlichiosis are the second-most common tick-borne diseases reported in 2019, after Lyme disease [20]. Eight states, including Vermont, Maine, Rhode Island, Minnesota, Massachusetts, Wisconsin, New Hampshire, and New York, account for around nine in 10 of all the reported cases of anaplasmosis [20].

Anaplasmosis usually presents non-specific symptoms such as fever, chills, malaise, myalgias, headache, and rarely a rash. There are also reports of non-specific gastrointestinal (G.I.) or respiratory symptoms [19]. Immunocompromised people might be at an increased risk of hospitalization and severe outcomes $[19,20]$. In addition, co-infection with other tick-borne organisms (Anaplasma, Lyme, and Babesia) may occur due to I. scapularis being the common vector [19].

Culture, histopathology, polymerase chain reaction (PCR), or serology is used to diagnose the disease. Intracytoplasmic aggregates of Anaplasma in peripheral blood neutrophils can be detected in $20 \%-80 \%$ of symptomatic patients. In infected patients, lymphoid organs (bone marrow, liver, spleen, and lymph nodes) show changes in mononuclear phagocytes. Lungs may also be affected due to the systemic inflammatory response. Periportal lymphohistiocytic infiltrates, focal splenic necrosis, mild interstitial pneumonitis, and pulmonary hemorrhage are also seen in severe cases with organ damage [19]. The treatment is detailed in Table 2. 


\section{Cureus}

\begin{tabular}{|c|c|c|c|}
\hline No. & Pathogen & First-Line Treatment & Additional Information \\
\hline 1 & $\begin{array}{l}\text { Anaplasma } \\
\text { phagocytophilum }\end{array}$ & $\begin{array}{l}\text { Doxycycline } 100 \mathrm{mg} \text { administered twice daily for } 14 \text { to } 21 \\
\text { days; OR at least three days after defervescence. If co- } \\
\text { infection with Lyme, give treatment for extra } 10 \text { days. }\end{array}$ & $\begin{array}{l}\text { Potential adverse effects of doxycycline: life- } \\
\text { threatening allergies and tooth discoloration in } \\
\text { children }<8 \text { years old. }\end{array}$ \\
\hline 2 & Babesia microti & $\begin{array}{l}\text { Atovaquone: } 750 \mathrm{mg} \text { orally twice a day + azithromycin: first } \\
\text { day: } 500-1000 \mathrm{mg} \text { orally; subsequent days: } 250-1000 \mathrm{mg} \text { per } \\
\text { day OR clindamycin: } 600 \mathrm{mg} \text { orally three times a day, or } 300- \\
600 \mathrm{mg} \text { IV every } 6 \text { hours + quinine: } 650 \mathrm{mg} \text { orally every } 8 \\
\text { hours. In addition to these, some patients, including severely } \\
\text { ill patients, might need additional supportive care. }\end{array}$ & $\begin{array}{l}\text { Quinine and clindamycin can be safely used to treat } \\
\text { symptomatic pregnant women. Atovaquone can be } \\
\text { administered with care in lactating women feeding } \\
\text { infants who weigh }<5 \mathrm{~kg} \text {. Atovaquone is considered to } \\
\text { be safe to be used in children who weigh }>5 \mathrm{~kg} \text {. } \\
\text { Weighing the benefits and risks, azithromycin can be } \\
\text { administered to pregnant and lactating women with } \\
\text { caution. From } 6 \text { months to } 16 \text { years of age, } \\
\text { azithromycin is considered a safe drug to treat } \\
\text { Babesiosis. Benzyl alcohol is present in the parenteral } \\
\text { form of clindamycin, which is known to cause } \\
\text { "Gasping Syndrome" in premature infants. }\end{array}$ \\
\hline 3 & $\begin{array}{l}\text { Borrelia } \\
\text { burgdorferi }\end{array}$ & $\begin{array}{l}\text { If }>8 \text { years old with early, localized sickness: doxycycline } 100 \\
\text { mg orally twice daily OR doxycycline } 200 \mathrm{mg} \text { once daily for } 10 \\
\text { days. Patient < } 8 \text { years old: amoxicillin } 500 \mathrm{mg} \text { orally three } \\
\text { times daily for } 14 \text { days OR cefuroxime orally three times daily } \\
\text { for } 14 \text { days. If the person is allergic or intolerant to } \\
\text { doxycycline, amoxicillin, and cefuroxime, they can be given } \\
\text { macrolides: azithromycin, clarithromycin, or erythromycin. } \\
\text { However, these drugs are of lower efficacy. People } \\
\text { undergoing macrolides treatment should be monitored. } \\
\text { Pregnancy: ceftriaxone. Carditis or CNS involvement: } \\
\text { ceftriaxone OR doxycycline. The ocular feature of zoonotic } \\
\text { disease: topical steroids + IV cephalosporin. }\end{array}$ & $\begin{array}{l}\text { Post-treatment, Lyme disease syndrome is } \\
\text { experienced by some patients. Antibiotics do not } \\
\text { resolve these symptoms. }\end{array}$ \\
\hline 4 & Bourbon virus & No medications; only symptomatic treatment. & - \\
\hline 5 & Powassan virus & $\begin{array}{l}\text { No specific medications. Severe disease, supportive } \\
\text { treatment with respiratory support, intravenous fluid steps to } \\
\text { reduce cerebral edema. POWV neuroinvasive disease: treated } \\
\text { with high-dose corticosteroids. POWV encephalitis treated } \\
\text { with IVIg. }\end{array}$ & - \\
\hline 6 & $\begin{array}{l}\text { Ehrlichia muris } \\
\text { eauclarensis }\end{array}$ & oxycycline $5-10 \mathrm{mg} / \mathrm{kg}$ every 12 hours for $5-7$ days. & - \\
\hline 7 & Borrelia mayonii & $\begin{array}{l}\text { Doxycycline } 100 \mathrm{mg} \text { orally twice daily or } 200 \mathrm{mg} \text { once daily for } \\
10 \text { days. }\end{array}$ & - \\
\hline 8 & $\begin{array}{l}\text { Borrelia } \\
\text { miyamotoi }\end{array}$ & $\begin{array}{l}\text { Tick-borne relapsing fever (TBRF): Adults: a } 7 \text {-day course of } \\
\text { oral or parenteral of chloramphenicol ( } 500 \mathrm{mg}) 6 \text { hourly daily } \\
\text { for } 7 \text { days OR doxycycline ( } 100 \mathrm{mg} \text { ) twice daily for } 7 \text { days OR } \\
\text { erythromycin }(500 \mathrm{mg}) 6 \text { hourly daily for } 7 \text { days OR tetracycline } \\
\text { ( } 500 \mathrm{mg} \text { oral } / 250 \mathrm{mg} \text { parental) } 6 \text { hourly daily for } 7 \text { days OR } \\
\text { parenteral penicillin G } 60,000 \mathrm{IU} \text { daily for } 7 \text { days. Children }<8 \\
\text { years or pregnant women: penicillin G or erythromycin. }\end{array}$ & $\begin{array}{l}\text { Jarisch-Herxheimer reaction with hypotension, } \\
\text { tachycardia, chills, rigors, diaphoresis, and marked } \\
\text { elevation of body temperature. Partial agonist } \\
\text { meptazinol seems to reduce the severity of these } \\
\text { symptoms due to Jarisch-Herxheimer's reaction; } \\
\text { death is also reported as this reaction's complication } \\
\text { secondary to cardiovascular collapse. }\end{array}$ \\
\hline
\end{tabular}

\section{TABLE 2: Treatment of black-legged ticks}

CNS, Central nervous system; POWV, Powassan virus.

\subsection{Babesia microti}

Babesiosis is caused by a protozoan (Piroplasmida: Babesiidae) that infects farm animals and causes zoonotic infection in humans [21]. Though there are more than 100 Babesia species, Babesia microti is the most common type, and it is transmitted by I. scapularis. In 2018, the CDC reported 2,161 cases of Babesiosis in the United States [22]. In 2019, 4.75\% of tick-borne infections were caused by B. microti [22]. 
Babesiosis can be acquired through the bite of an infected tick or by receiving a blood transfusion from an asymptomatic infected donor or rarely through vertical transmission [22]. Tonnetti et al. conducted a clinical trial with blood donation samples from Massachusetts, Connecticut, Minnesota, and Wisconsin. They screened (by immunoassay and PCR) 5,06,540 donations from June 2012 to May 2018 for B. microti, of which 1299 were positive. They propose that by deploying routine screening of $B$. microti in endemic areas, transfusion-transmitted Babesiosis can be mitigated [23]. The clinical manifestations of the disease are due to the multiplication of the blood-stage parasites, and that can even cause lysis of the erythrocytes [24].

Most of the individuals affected by Babesiosis appear to be asymptomatic. However, a group of elderly and immunocompromised patients, including asplenic patients, are at increased risk of developing adverse clinical complications such as hemolysis, thrombocytopenia, acute respiratory distress, renal failure, hepatic compromise, disseminated intravascular coagulation (DIC), altered mental status, and multiorgan failure ultimately causing death $[21,25]$. Some patients might require supportive care, such as antipyretics, vasopressors, blood transfusions, exchange transfusions, mechanical ventilation, or dialysis [26]. However, asymptomatic patients usually do not need to be treated [26]. The combination of drug therapy is detailed in Table 2.

\subsection{Borrelia burgdorferi}

Borrelia burgdorferi is a spirochete, transmitted by I. scapularis. It is the causative agent of a zoonotic infection commonly known as Lyme disease [27]. Lyme disease burden is high. In 2018, the estimated cost for acute disease treatment was $\$ 4.8$ billion and for chronic disease was $\$ 9.6$ billion in the United States [28]. In the northeastern and midwestern United States, it is mainly transmitted by $I$. scapularis and in the western states by Ixodes pacificus [29]. Clinically, Lyme disease manifests in three stages seen at different intervals from the tick bite [29]. Within days to weeks of a tick bite, $70 \%-80 \%$ of patients present with a "bull's eye rash," also known as "target rash" or erythema migrans; a diagnostic feature of the disease [29,30] is commonly seen on the thighs, groin, and the axilla [31].

The early or disseminated phase occurs after few weeks to months, characterized by fever, headache, migratory arthralgias, myalgias, headache, fatigue, neurological (20\%), and cardiac manifestations in some cases [2,29,32]. Lymphocytic meningitis, facial nerve palsy (5\%), and sensory or motor radiculoneuritis are commonly seen neurological features in the United States [2,29]. Cardiac complications may occur in around $0.3 \%-10 \%$ of Lyme disease patients and include atrioventricular blocks of varying degrees, myopericarditis, or cardiomegaly [31].

After months to years, Lyme arthritis, commonly involving the knee joint, is seen in stage 3 or Late Lyme disease, especially in people who do not receive treatment in the early stage of the disease [2,29,32]. Lyme disease can be diagnosed either clinically or by laboratory methods. The latter are of two types, direct or indirect methods. Direct diagnostic tests include PCR assays [33,34]. Indirect tests include enzyme-linked immunosorbent assays (ELISA) and western blot [33]. CDC recommends a two-step testing process (positive ELISA followed by western blot) to detect Lyme disease [35]. However, recently, CDC has suggested that a consecutive ELISA test can be used as an alternative to the western blot test [36]. The treatment [2,34,37] is detailed in Table 2.

\subsection{Bourbon virus}

Bourbon virus (BRBV) was identified first in a patient with fever and a history of tick bite in Bourbon County, Kansas City, United States [38]. Subsequently, other human BRBV infections were reported from the midwestern and southern United States [39]. BRBV belongs to the Orthomyxoviridae family and Thogotovirus genus worldwide $[38,40]$. The genus Thogotovirus has a negative-sense RNA genome of six segments. Thogotovirus is transmitted by both hard or soft ticks [41]. I. scapularis and Lone star tick, Amblyomma americanum, are associated with BRBV transmission in humans and other vertebrates $[42,43]$.

BRBV prevalence in potential vectors remains unclear; additional field studies are required. However, the very low infectious nymph prevalence and varied male adult rates show that other transmission cycles for BRBV might be possible [39]. Patients with impaired innate immunity might be at the risk of severe BRBV infection and benefit from an antiviral treatment like ribavirin and favipiravir [44]. BRBV infections have been identified with a history of tick bites associated with fever, rash, headache, malaise, nausea, vomiting, thrombocytopenia, and leukopenia [40]. The treatment [45] is detailed in Table 2.

\subsection{Powassan virus}

Powassan virus (POWV), a member of the tick-borne encephalitis serocomplex of flavivirus, causes Powassan disease [46]. It was first identified in a young boy in 1958 who died with encephalitis in Powassan, Ontario, Canada [47]. The genome of POWV includes $11 \mathrm{~kb}$ of single-stranded, positive-sense RNA. There is only limited data available regarding the various strains and genomic studies on POWV [48-50]. However, POWV replication and its causation in humans are known by research on the closely associated tick-borne encephalitis virus (TBEV) [51]. The TBEV genome and the POWV genome consist of single-stranded, 
positive-sense RNA [52]. POWV has two distinct genotypes that are serologically difficult, and both are transmitted through ticks: POW lineage 1 (POW-L1) and deer tick virus or POWV lineage 2 (DTV). However, in POWV, lineage I is maintained by Ixodes cookei, also known as the Groundhog ticks, whereas DTV lineage II is maintained by I. scapularis [49].

POWV causes rare severe neuroinvasive diseases in humans. The incubation period ranges between one and five weeks. The prodromal phase includes headache, sore throat, drowsiness, and disorientation, followed by severe neurological involvement with encephalitis, meningoencephalitis, and aseptic meningitis. The encephalitis phase includes prolonged fever, vomiting, speech difficulties, loss of coordination, seizures, and paralysis [51]. Over 50\% of survivors from encephalitis might end up with several long-lasting neurological sequelae, including memory problems, hemiplegia, muscle wasting, and severe headache [49]. Diagnosis of POWV during the early viremic phase of the disease is made by detecting specific nucleic acid or viral antigen and by viral isolation. In later stages of the disease, detection of POWV-specific IgM and IgG antibodies by serological testing is diagnostic [51]. Most of the studies show non-specific magnetic resonance imaging (MRI) abnormalities for POWV cases. However, certain studies show that MRI in POWV patients shows T2/fluid attenuation inversion recovery (FLAIR) hyperintensities within the brainstem and extensions into deep gray structures and cortex [49]. POWV and DTV are usually serologically indistinguishable, but recent studies show that PCR primers specific to the envelope-coding region (NS5 coding region) can be used to differentiate them [53]. The treatment [49,53-55] is detailed in Table 2.

\subsection{Ehrlichia muris eauclarensis}

Ehrlichia species is an obligate intracellular bacteria transmitted by hard ticks. Most of the Ehrlichia are transmitted by the Amblyomma americanum tick, prevalent in southeast, south-central, and mid-Atlantic states. Nevertheless, the Ehrlichia muris-like (EML) genus of Ehrlichia is transmitted by I. scapularis, especially in Wisconsin and Minnesota [13].

In an epidemiologic study of EML in 69 patients between 2004 and 2013, it was found that symptoms due to EML are more common in immunocompromised patients [56]. Sixty percentage of children and 30\% of adults with Ehrlichiosis present with skin rash [57]. Ehrlichiosis presents with symptoms such as fever, malaise, headache, and myalgia. The common hematologic picture in them are anemia, thrombocytopenia, lymphopenia, leukopenia, and increased aspartate aminotransferase and alanine aminotransferase enzymes. They also noted that two patients were co-infected with B. burgdorferi [56]. The rare complications occurring in patients with Ehrlichiosis are renal failure, acute respiratory distress syndrome, neurologic disorders, and DIC [58]. Ehrlichiosis is diagnosed clinically based on signs and symptoms, history of a tick bite, and exposure to the endemic areas and confirmed by laboratory tests such as PCR, indirect immunofluorescence antibody (IFA) assay for immunoglobulin G (IgG), culture isolation, and immunohistochemical assays. However, treatment must be initiated promptly without waiting for the lab reports [57]. The treatment [57] is detailed in Table 2.

\subsection{Borrelia mayonii}

Borrelia mayonii species nova has recently been reported as a unique spirochete inflicting Lyme disease in North America [59]. The morphology matches that of antecedently delineated species of the genus Borrelia. B. mayonii is often distinguished from all different Lyme Borreliosis-group spirochetes by multi-locus sequence analysis of eight housework loci [60]. Patients infected with B. mayonii present with either focal or diffuse rash, nausea, vomiting, along with neurological symptoms in some cases $[59,60]$. PCR shows a high spirochete load in the blood during the acute phase of the infection [60]. The treatment [4] is detailed in Table 2.

\subsection{Borrelia miyamotoi}

Borrelia miyamotoi (B. miyamotoi) is known to be one of the causative agents of B. miyamotoi disease (BMD), also known as hard tick-borne relapsing fever (TBRF) [61] transmitted by I. scapularis in the United States [62]. Additionally, in a study done by Jobe et al. (2016), seven cases of typical relapsing fever caused by $B$. miyamotoi were confirmed in Wisconsin [63]. BMD is characterized by episodes of high fever, nausea arthralgia, myalgia, nausea, arthralgia, myalgia, and fatigue, which can last for several weeks post-antibiotic therapy [64,65]. Monocytosis and thrombocytopenia are classically seen in American BMD [65]. In addition, elderly patients and immunocompromised patients can present with neurological complications such as meningoencephalitis [64]. The treatment [66,67] is detailed in Table 2.

\section{Alpha-gal syndrome}

Alpha-gal syndrome (AGS) is an IgE antibody-mediated allergic reaction to galactose sugar at alpha 1,3 position [68]. Typically, patients who have tolerated mammalian meat for many years suddenly develop an allergic reaction after being sensitized by a tick bite. Alpha-galactose sugar is found in the tick's saliva $[69,70]$. Though bite by the Lone Star ticks (A. americanum) is the most common cause of sensitizer for the alpha-gal allergic reaction [71], black-legged ticks are also known to precipitate this condition [72,73]. On 
exposure to mammalian meat, or products (medications, cosmetics, gelatin, etc.), sensitized patients experience allergic symptoms (from mild to life-threatening). These symptoms range from pruritus, rash, nausea, vomiting, and dizziness to breathing difficulty and hypotensive shock [74]. The management for AGS is the same as that for any other allergic reaction, with epinephrine, antihistamines, and in case of shock with vasopressors and fluid. AGS can be prevented by preventing tick bites [74], and sensitized individuals should avoid foods and products, which contain alpha-gal [75].

\section{Public health strategies for prevention and treatment of tick-borne disease}

Various public health strategies recommended against tick-borne infections are effective educational interventions for promoting behavioral modification. These include promoting the use of repellents, wearing protective clothing while in endemic areas, checking for ticks, and removing them at the earliest. The definitively preventive measure of vaccination against tick-borne infections is also under trial $[76,77]$.

\section{Current significance of tick-borne infections amid the ongoing pandemic situation}

Due to the COVID-19 pandemic, either misdiagnosis or delayed diagnosis of tick-transmitted infection has been reported. This was mainly because of non-specific, overlapping early symptoms. The overlapping symptoms were febrile illnesses, fatigue, or body aches [78]. Wormser et al. reported that patients were initially tested for COVID-19; once ruled out, they were subsequently tested for other pathogens. Due to the delay in diagnosis and treatment, the patient developed cardiac complications from Lyme disease. Skin rash was missed because the initial consultation was a teleconsultation [11]. Tick exposure season was ongoing in the spring of 2020 at the onset of the pandemic. Since screening for COVID-19 symptoms was not yet specific, late diagnosis of Lyme disease led to ocular palsy due to disseminating infection [78].

Jha et al. explored significant complications that could arise in the late or misdiagnosis of Lyme disease. One major complication, although uncommon, is optic neuritis that was observed in a patient infected with $B$. burgdorferi. Other complications included joint involvement, meningitis, skin lesions, carditis, and cranial nerve involvement. To treat neurological complications of Lyme disease, ceftriaxone, cefotaxime, and penicillin $\mathrm{G}$ are indicated. Another highly effective antibiotic is oral doxycycline. Early diagnosis is crucial to prevent irreversible complications [79]. It is recommended that in high endemic areas or patients with a known history of tick bites, appropriate testing should be conducted simultaneously as COVID-19 tests to prevent delayed diagnosis leading to complications. Rose et al. has reported patients who tested positive for COVID-19 and Lyme disease. The Global Lyme Alliance has reported cases of COVID-19 in patients with chronic tick-borne co-infections with Lyme, Ehrlichia, and Babesia. They mention that due to immunosuppressive medications such as hydroxychloroquine, which these patients are prescribed, there is an increased chance of false-negative COVID-19 tests [80]. So far, they have not recorded any increased severity of symptoms or risk of complications due to COVID-19 in patients with pre-existing chronic tickborne infections. Limited data is available regarding COVID-19 mRNA vaccination in patients with chronic tick-borne infections like Lyme disease [81].

\section{Conclusions}

The tick-borne infections cause a social and economic burden in the United States, and a co-infection of various bacteria, viruses, and protozoa is common with the tick bite. Ongoing pandemic situation further aggravated this by creating a diagnostic dilemma due to overlapping of symptoms or co-infection or superadded infection, non-conclusive tests, and increased transfer of primary care to the telehealth version. Active public health promotion measures must be taken in the endemic areas to encourage preventive measures against tick-borne infections. Prospective cohort studies in the endemic areas are needed to help reverse the increasing number of cases.

\section{Additional Information \\ Disclosures}

Conflicts of interest: In compliance with the ICMJE uniform disclosure form, all authors declare the following: Payment/services info: All authors have declared that no financial support was received from any organization for the submitted work. Financial relationships: All authors have declared that they have no financial relationships at present or within the previous three years with any organizations that might have an interest in the submitted work. Other relationships: All authors have declared that there are no other relationships or activities that could appear to have influenced the submitted work.

\section{References}

1. Wolf MJ, Watkins HR, Schwan WR: Ixodes scapularis: vector to an increasing diversity of human pathogens in the upper midwest. WMI. 2020, 119:16-21.

2. Skar GL, Simonsen KA: Lyme Disease. StatPearls Publishing, Treasure Island, FL; 2021.

3. Nelson CA, Saha S, Kugeler KJ, Delorey MJ, Shankar MB, Hinckley AF, Mead PS: Incidence of clinician- 
diagnosed Lyme disease, United States, 2005-2010. Emerg Infect Dis. 2015, 21:1625-31. 10.3201/eid2109.150417

4. Madison-Antenucci S, Kramer LD, Gebhardt LL, Kauffman E: Emerging tick-borne diseases. Clin Microbiol Rev. 2020, 33:e00083-18. 10.1128/CMR.00083-18

5. Eisen RJ, Kugeler KJ, Eisen L, Beard CB, Paddock CD: Tick-borne zoonoses in the united states: persistent and emerging threats to human health. ILAR J. 2017, 58:319-35. 10.1093/ilar/ilx005

6. Preventing tick bites. (2019). Accessed: June 15, 2021: https://www.cdc.gov/ticks/avoid/on_people.html.

7. Mac S, da Silva SR, Sander B: The economic burden of Lyme disease and the cost-effectiveness of Lyme disease interventions: a scoping review. PLoS One. 2019, 14:e0210280. 10.1371/journal.pone.0210280

8. Zhang X, Meltzer MI, Peña CA, Hopkins AB, Wroth L, Fix AD: Economic impact of Lyme disease . Emerg Infect Dis. 2006, 12:653-60. 10.3201/eid1204.050602

9. Adrion ER, Aucott J, Lemke KW, Weiner JP: Health care costs, utilization and patterns of care following Lyme disease. PLoS One. 2015, 10:e0116767. 10.1371/journal.pone.0116767

10. Mattingly TJ 2nd, Shere-Wolfe K: Clinical and economic outcomes evaluated in Lyme disease: a systematic review. Parasit Vectors. 2020, 13:341. 10.1186/s13071-020-04214-y

11. Wormser GP, Jacobson E, Shanker EM: Negative impact of the COVID-19 pandemic on the timely diagnosis of tick-borne infections. Diagn Microbiol Infect Dis. 2021, 99:115226. 10.1016/j.diagmicrobio.2020.115226

12. Moniuszko-Malinowska A, Pancewicz S, Czupryna P: Has COVID-19 influenced on tick-borne epidemiology?. Przegl Epidemiol. 2020, 74:740-1. 10.32394/pe.74.65

13. Daltroy LH, Phillips C, Lew R, Wright E, Shadick NA, Liang MH: A controlled trial of a novel primary prevention program for Lyme disease and other tick-borne illnesses. Health Educ Behav. 2007, 34:531-42. $10.1177 / 1090198106294646$

14. Eisen RJ, Eisen L: The blacklegged tick, Ixodes scapularis: an increasing public health concern . Trends Parasitol. 2018, 34:295-309. 10.1016/j.pt.2017.12.006

15. Stewart PE, Bloom ME: Sharing the ride: Ixodes scapularis symbionts and their interactions . Front Cell Infect Microbiol. 2020, 10:142. 10.3389/fcimb.2020.00142

16. Villar M, López V, Ayllón N, et al.: The intracellular bacterium Anaplasma phagocytophilum selectively manipulates the levels of vertebrate host proteins in the tick vector Ixodes scapularis. Parasit Vectors. 2016, 9:467. 10.1186/s13071-016-1747-3

17. Soosaraei M, Haghi MM, Etemadifar F, Fakhar M, Teshnizi SH, Asfaram S, Esboei BR: Status of Anaplasma spp. infection in domestic ruminants from Iran: a systematic review with meta-analysis. Parasite Epidemiol Control. 2020, 11:e00173. 10.1016/j.parepi.2020.e00173

18. Vaillant AAJ, Sticco KL: Transfusion Transmitted Disease. StatPearls Publishing, Treasure Island, FL; 2021.

19. Guzman N, Yarrarapu SN, Beidas SO: Anaplasma Phagocytophilum. StatPearls Publishing, Treasure Island, FL; 2021.

20. Anaplasmosis. (2019). Accessed: June 29, 2021: https://www.cdc.gov/anaplasmosis/index.html.

21. Onyiche TE, Răileanu C, Fischer S, Silaghi C: Global distribution of Babesia species in questing ticks: a systematic review and meta-analysis based on published literature. Pathogens. 2021, 10:230. 10.3390/pathogens 10020230

22. Parasites - Babesiosis. (2021). Accessed: June 29, 2021: https://www.cdc.gov/parasites/babesiosis/index.html.

23. Tonnetti L, Townsend RL, Deisting BM, Haynes JM, Dodd RY, Stramer SL: The impact of Babesia microti blood donation screening. Transfusion. 2019, 59:593-600. 10.1111/trf.15043

24. Parasites - Babesiosis: Biology. (2019). Accessed: July 4, 2021: http://www.cdc.gov/parasites/babesiosis/biology.html.

25. Dumic I, Madrid C, Rueda Prada L, Nordstrom CW, Taweesedt PT, Ramanan P: Splenic complications of Babesia microti Infection in humans: a systematic review. Can J Infect Dis Med Microbiol. 2020, 2020:6934149. 10.1155/2020/6934149

26. Babesiosis: Resources for health professionals. (2019). Accessed: July 4, 2021: http://www.cdc.gov/parasites/babesiosis/health_professionals/index.html.

27. Brisson D, Drecktrah D, Eggers CH, Samuels DS: Genetics of Borrelia burgdorferi. Annu Rev Genet. 2012, 46:515-36. 10.1146/annurev-genet-011112-112140

28. Rogalska AM, Pawełczyk O, Solarz K, Holecki T: What are the costs of diagnostics and treatment of Lyme borreliosis in Poland?. Front Public Health. 2020, 8:599239. 10.3389/fpubh.2020.599239

29. Steere AC, Strle F, Wormser GP, et al.: Lyme borreliosis. Nat Rev Dis Primers. 2016, 2:16090. 10.1038/nrdp.2016.90

30. Sanchez E, Vannier E, Wormser GP, Hu LT: Diagnosis, treatment, and prevention of Lyme disease, human granulocytic anaplasmosis, and Babesiosis: a review. JAMA. 2016, 315:1767-77. 10.1001/jama.2016.2884

31. Tatum R, Pearson-Shaver AL: Borrelia Burgdorferi. StatPearls Publishing, Treasure Island, FL; 2021.

32. Bockenstedt LK, Wormser GP: Review: unraveling Lyme disease . Arthritis Rheumatol. 2014, 66:2313-23. 10.1002/art.38756

33. John TM, Taege AJ: Appropriate laboratory testing in Lyme disease . Cleve Clin J Med. 2019, 86:751-9. 10.3949/ccjm.86a.19029

34. Marques AR: Laboratory diagnosis of Lyme disease: advances and challenges . Infect Dis Clin North Am. 2015, 29:295-307. 10.1016/j.idc.2015.02.005

35. Lyme disease - Diagnosis and testing . (2015). Accessed: June 29, 2021: http://www.cdc.gov/lyme/diagnosistesting/.

36. Mead P, Petersen J, Hinckley A: Updated CDC recommendation for serologic diagnosis of Lyme disease . MMWR Morb Mortal Wkly Rep. 2019, 68:703. 10.15585/mmwr.mm6832a4

37. Lantos PM, Rumbaugh J, Bockenstedt LK, et al.: Clinical Practice Guidelines by the Infectious Diseases Society of America (IDSA), American Academy of Neurology (AAN), and American College of Rheumatology (ACR): 2020 Guidelines for the prevention, diagnosis and treatment of Lyme disease. Clin Infect Dis. 2021, 72:e1-e48. 10.1093/cid/ciaa1215

38. Kosoy OI, Lambert AJ, Hawkinson DJ, Pastula DM, Goldsmith CS, Hunt DC, Staples JE: Novel thogotovirus 
associated with febrile illness and death, United States, 2014. Emerg Infect Dis. 2015, 21:760-4. 10.3201/eid2105.150150

39. Savage HM, Burkhalter KL, Godsey MS Jr, Panella NA, Ashley DC, Nicholson WL, Lambert AJ: Bourbon virus in field-collected ticks, Missouri, USA. Emerg Infect Dis. 2017, 23:2017-22. 10.3201/eid2312.170532

40. Lambert AJ, Velez JO, Brault AC, et al.: Molecular, serological and in vitro culture-based characterization of Bourbon virus, a newly described human pathogen of the genus Thogotovirus. J Clin Virol. 2015, 73:127-32. 10.1016/j.jcv.2015.10.021

41. Hubálek Z, Rudolf I: Tick-borne viruses in Europe. Parasitol Res. 2012, 111:9-36. 10.1007/s00436-012-29101

42. Savage HM, Godsey MS Jr, Tatman J, et al.: Surveillance for Heartland and Bourbon Viruses in Eastern Kansas, June 2016. J Med Entomol. 2018, 55:1613-6. 10.1093/jme/tjy103

43. Jackson KC, Gidlewski T, Root JJ, et al.: Bourbon virus in wild and domestic animals, Missouri, USA, 20122013. Emerg Infect Dis. 2019, 25:1752-3. 10.3201/eid2509.181902

44. Fuchs J, Straub T, Seidl M, Kochs G: Essential role of interferon response in containing human pathogenic Bourbon virus. Emerg Infect Dis. 2019, 25:1304-13. 10.3201/eid2507.181062

45. Bourbon virus - Symptoms, diagnosis, and treatment. (2021). Accessed: June 29, 2021: https://www.cdc.gov/bourbon-virus/symptoms-diagnosis-treatment/index.html.

46. Gholam BI, Puksa S, Provias JP: Powassan encephalitis: a case report with neuropathology and literature review. CMAJ. 1999, 161:1419-22.

47. McLean DM, Donohue WL: Powassan virus: isolation of virus from a fatal case of encephalitis . Can Med Assoc J. 1959, 80:708-11.

48. Ebel GD: Update on Powassan virus: emergence of a North American tick-borne flavivirus . Annu Rev Entomol. 2010, 55:95-110. 10.1146/annurev-ento-112408-085446

49. Piantadosi A, Rubin DB, McQuillen DP, et al.: Emerging cases of Powassan virus encephalitis in New England: clinical presentation, imaging, and review of the literature. Clin Infect Dis. 2016, 62:707-13. 10.1093/cid/civ1005

50. Kuno G, Artsob H, Karabatsos N, Tsuchiya KR, Chang GJ: Genomic sequencing of deer tick virus and phylogeny of Powassan-related viruses of North America. Am J Trop Med Hyg. 2001, 65:671-6. 10.4269/ajtmh.2001.65.671

51. Hermance ME, Thangamani S: Powassan virus: an emerging Arbovirus of public health concern in North America. Vector Borne Zoonotic Dis. 2017, 17:453-62. 10.1089/vbz.2017.2110

52. Calisher CH, Karabatsos N, Dalrymple JM, Shope RE, Porterfield JS, Westaway EG, Brandt WE: Antigenic relationships between flaviviruses as determined by cross-neutralization tests with polyclonal antisera. J Gen Virol. 1989, 70:37-43. 10.1099/0022-1317-70-1-37

53. El Khoury MY, Hull RC, Bryant PW, et al.: Diagnosis of acute deer tick virus encephalitis . Clin Infect Dis. 2013, 56:e40-7. 10.1093/cid/cis938

54. Sung S, Wurcel AG, Whittier S, et al.: Powassan meningoencephalitis, New York, New York, USA . Emerg Infect Dis. 2013, 19:1504-1506. 10.3201/eid1909.121846

55. Hicar MD, Edwards K, Bloch K: Powassan virus infection presenting as acute disseminated encephalomyelitis in Tennessee. Pediatr Infect Dis J. 2011, 30:86-8. 10.1097/INF.0b013e3181f2f492

56. Johnson DK, Schiffman EK, Davis JP, et al.: Human Infection with Ehrlichia muris-like Pathogen, United States, 2007-2013(1). Emerg Infect Dis. 2015, 21:1794-9. 10.3201/eid2110.150143

57. Ehrlichiosis - Treatment. (2021). Accessed: June 29, 2021: https://www.cdc.gov/ehrlichiosis/healthcareproviders/treatment.html.

58. McQuiston JH, McCall CL, Nicholson WL: Ehrlichiosis and related infections. J Am Vet Med Assoc. 2003, 223:1750-6. 10.2460/javma.2003.223.1750

59. Walter L, Sürth V, Röttgerding F, Zipfel PF, Fritz-Wolf K, Kraiczy P: Elucidating the immune evasion mechanisms of Borrelia mayonii, the causative agent of Lyme disease. Front Immunol. 2019, 10:2722. 10.3389/fimmu.2019.02722

60. Pritt BS, Respicio-Kingry LB, Sloan LM, et al.: Borrelia mayonii sp. nov., a member of the Borrelia burgdorferi sensu lato complex, detected in patients and ticks in the upper midwestern United States. Int J Syst Evol Microbiol. 2016, 66:4878-80. 10.1099/ijsem.0.001445

61. Tick-borne relapsing fever. (2021). Accessed: July 5, 2021: https://www.cdc.gov/relapsing-fever/index.html.

62. Krause PJ, Narasimhan S, Wormser GP, et al.: Human Borrelia miyamotoi infection in the United States . N Engl J Med. 2013, 368:291-3. 10.1056/NEJMc1215469

63. Jobe DA, Lovrich SD, Oldenburg DG, Kowalski TJ, Callister SM: Borrelia miyamotoi infection in patients from upper midwestern United States, 2014-2015. Emerg Infect Dis. 2016, 22:1471-3. 10.3201/eid2208.151878

64. Krause PJ, Fish D, Narasimhan S, Barbour AG: Borrelia miyamotoi infection in nature and in humans . Clin Microbiol Infect. 2015, 21:631-9. 10.1016/j.cmi.2015.02.006

65. Kubiak K, Szczotko M, Dmitryjuk M: Borrelia miyamotoi-an emerging human tick-borne pathogen in Europe. Microorganisms. 2021, 9:10.3390/microorganisms9010154

66. Dworkin MS, Schwan TG, Anderson DE Jr, Borchardt SM: Tick-borne relapsing fever. Infect Dis Clin North Am. 2008, 22:449-68. 10.1016/j.idc.2008.03.006

67. Griffin GE: Cytokines involved in human septic shock--the model of the Jarisch-Herxheimer reaction . J Antimicrob Chemother. 1998, 41:25-9. 10.1093/jac/41.suppl_1.25

68. Commins SP, Satinover SM, Hosen J, et al.: Delayed anaphylaxis, angioedema, or urticaria after consumption of red meat in patients with IgE antibodies specific for galactose-alpha-1,3-galactose. J Allergy Clin Immunol. 2009, 123:426-33. 10.1016/j.jaci.2008.10.052

69. Cabezas-Cruz A, Valdés J, de la Fuente J: Cancer research meets tick vectors for infectious diseases. Lancet Infect Dis. 2014, 14:916-917. 10.1016/S1473-3099(14)70902-8

70. van Nunen S, O’Connor K, Fernando S, Clarke L, Boyle RX: The association between Ixodes holocyclus tick bitereactions and red meat allergy | Ascia 2007 Allergic disease posters. Intern Med J. 2007, 37:A125-58. 10.1111/j.1445-5994.2007.01551.x 
71. Commins SP, James HR, Kelly LA, et al.: The relevance of tick bites to the production of IgE antibodies to the mammalian oligosaccharide galactose- $\alpha$-1,3-galactose. J Allergy Clin Immunol. 2011, 127:1286-93.e6. 10.1016/j.jaci.2011.02.019

72. Crispell G, Commins SP, Archer-Hartman SA, Choudhary S, Dharmarajan G, Azadi P, Karim S: Discovery of alpha-gal-containing antigens in North American tick species believed to induce red meat allergy. Front Immunol. 2019, 10:1056. 10.3389/fimmu.2019.01056

73. Apostolovic D, Mihailovic J, Commins SP, et al.: Allergenomics of the tick Ixodes ricinus reveals important $\alpha$-gal-carrying IgE-binding proteins in red meat allergy. Allergy. 2020, 75:217-20. 10.1111/all.13978

74. Alpha-gal syndrome. (2021). Accessed: July 4, 2021: https://www.cdc.gov/ticks/alpha-gal/index.html.

75. Platts-Mills TA, Li RC, Keshavarz B, Smith AR, Wilson JM: Diagnosis and management of patients with the $\alpha$-gal syndrome. J Allergy Clin Immunol Pract. 2020, 8:15-23.e1. 10.1016/j.jaip.2019.09.017

76. Mowbray F, Amlôt R, Rubin GJ: Ticking all the boxes? A systematic review of education and communication interventions to prevent tick-borne disease. Vector Borne Zoonotic Dis. 2012, 12:817-25. 10.1089/vbz.2011.0774

77. Richardson M, Khouja C, Sutcliffe K: Interventions to prevent Lyme disease in humans: a systematic review . Prev Med Rep. 2019, 13:16-22. 10.1016/j.pmedr.2018.11.004

78. Novak CB, Scheeler VM, Aucott JN: Lyme disease in the era of COVID-19: a delayed diagnosis and risk for complications. Case Rep Infect Dis. 2021, 2021:6699536. 10.1155/2021/6699536

79. Jha P, Pereira SGR, Thakur A, Jhaj G, Bhandari S: A case of optic neuritis secondary to Lyme disease . WMJ. 2018, 117:83-7.

80. What happens when coronavirus and Lyme disease intersect? . (2020). Accessed: July 1, 2021: https://www.lymedisease.org/covid-lyme-intersect-usa-today/.

81. COVID-19 vaccines for people with underlying medical conditions . (2021). Accessed: July 1, 2021: https://www.cdc.gov/coronavirus/2019-ncov/vaccines/recommendations/underlying-conditions.html. 